ИСТОРИЯ

\title{
«МИРАЖИ - ЭТО НАША ЖИЗНЬ». ИСТОРИЧЕСКАЯ МИФОЛОГИЯ И ФАЛЬСИФИКАЦИИ ИСТОРИИ"
}

\author{
О. А. Плотникова \\ (Московский гуманитарный университет)
}

\begin{abstract}
Аннотация: Статья посвящена анализу соотношения понятий «миф» и «фальсификация» применительно к истории России и подготовлена в рамках работы над исследованием «Влияние исторических фальсификаций и мифов на сознание и социальное поведение современной российской молодежи». В статье прослежена периодизация исторической мифологии, формулируются определения понятий «миф» и «фальсификация», показано их принциииальное различие.
\end{abstract} мифология.

Ключевые слова: мифы, фальсификации, история, история России, историческая

\section{“MIRAGE IS OUR LIFE”. HISTORICAL MYTHOLOGY AND FALSIFICATION OF HISTORY}

\author{
O. A. Plotnikova \\ (Moscow University for the Humanities)
}

\begin{abstract}
This article considers the correlation between the concepts of «myth» and «falsification» as applied to the history of Russia. It has been prepared within the framework of the study titled «The impact of historical falsifications and myths on the consciousness and social behavior of contemporary Russian youth.» The article traces the periodization of the historical mythology, provides the definitions of «myth» and «falsification» and shows their fundamental difference.
\end{abstract}

Keywords: myth, falsifications, history, Russian history, historical mythology, definitions.

В древности, когда история, как наука, еще только формировалась в недрах человеческого разума, но термин «история» уже существовал, его смысл сводился к установлению истинности событий и фактов. Прошло со-всем немного времени, и новорожденная наука история уже вмещала в себя новый смысл - рассказ о прошлом человечества. Однако рассказ этот оказался во многом легендарен, мифологизирован, а в некоторых случаях даже фальсифицирован. Во мраке столетий как-то незаметно

* Статья подготовлена в рамках проекта «Влияние исторических фальсификаций и мифов на сознание и социальное поведение современной российской молодежи». При реализации проекта используются средства государственной поддержки, выделенные в качестве гранта в соответствии с распоряжением Президента Российской Федерации от 17.01.2014 № 11-рп и на основании конкурса, проведенного Фондом ИСЭПИ.

This article was prepared as part of the project «The influence of historical falsifications and myths on the consciousness and social behavior of modern Russian youth.» The project has been supported with a state grant on the basis of the competition held by the Institute of Social-Economic and Political Research Foundation in accordance with the decree of the President of the Russian Federation № 11-RP of 17.01.2014. 
для всего человечества изначальная трактовка понятия истории потеряла колорит и первозданность, выцвел и вымылся основной его смысл, заключающийся в понятии - подлинность. Из века в век человек учился подделывать факты и исторические события, писать и переписывать историю в угоду политики, идеологии или прихоти и, надо сказать, очень в этом преуспел. В результате мы получили историю многократно переписанную, подтасованную, местами «прилизанную» и малоправдивую; и это касается всех без исключения стран и народов. В связи с этим сейчас, как, впрочем, и во все времена, вновь возникла потребность в пересмотре исторического знания и в справедливой его оценке на основании историчности и беспристрастности.

Но, прежде чем вновь взяться за переписывание истории, хотя бы своего Отечества, необходимопонять, почему история, а в первоначальном смысле «рассказ о прошлом», вмещает в себя столько неправдоподобных элементов, как, собственно, все эти элементы, неразрывно связанные с правдивой историей, называются, и главное, - как к ним относиться?

Начнем по порядку. Сначала постараемся разобраться, как вообще ложь и вымысел закрались на страницы истории, в результате чего история в некоторых случаях даже потеряла свое лицо. А случилось это, вероятно, потому что ложь как вчера, так и сегодня, являлась и является основным инструментом получения доходов для махинаторов и интриганов, коими всегда кишела и кишит земля наша обетованная. Правда, человечество для спасения «души», наверное, давно вывело удобную для себя формулу лжи: ложь во спасение - спасительная ложь, а ложь разрушающая - губительная. Ложь во спасение, если пристальнее всмотреться в прошлое, а может быть, и заглянуть в свою душу, даже иногда помогает и придает жизненные силы. Вспомним хотя бы известную драму М. Горького «На дне», где «бывшие люди» словно получают билет в новую жизнь благодаря выдумкам Луки. Обнадеженные, они меняются к лучшему однако эйфория была недолгой... А вот губительная ложь - это зло, которое должно быть искоренимо!

Теперь постараемся классифицировать все эти неправдоподобные составляющие истории, а потом уже определиться в своем отношении к ним. На мой взгляд, в данном случае достаточно будет разделить их на две основные группы, где первую составляют легенды и мифы, а вторую - фальсификации. Понятия неоднозначные, и определяют их по-разному (см.: Ручкин, 2011: Электр. ресурс; Плотникова, 2013). Разберемся в смысловой нагрузке каждого из приведенных понятий, а затем перейдем к их оценке.

Начнем с категории «ложь во спасение», т. е. с группы легенд и мифов. История легенд и мифов сравнима по длине временного отрезка с существованием самой истории как рассказа о прошлом. Легенды и мифы 
тоже повествует о прошлом. Только вот в отличие от историидостоверность этого прошлого недоказуема. Приведем здесь определения самим понятиям «легенда» и «миф», которые помогут нам разобраться в содержательной стороне вопроса. Начнем с легенды. В соответствии с определением, приводимым в Большом энциклопедическом словаре, «легенда - это рассказ, притча; в фольклоре - вошедший в традицию народный рассказ о чудесном; в новейшей литературе всякое произведение, отличающееся поэтическим вымыслом, но претендующее на некую достоверность в прошлом; в обиходном значении - что-то невероятное, выдумка» (Легенда, Электр. ресурс).

Итак, очевидно, что легенда - это неправдоподобный рассказ. Но при этом цели его весьма благородны - возвышение веры, воспевание праведности и, конечно, патриотизм. В процессе развития истории легенды утратили свое первоначальное значениев смысле религиознодидактического повествования и сблизились по смысловой нагрузке с мифам. И так как мифы не потеряли своей актуальности и в наше время, остановимся на них поподробнее.

Определение мифа тоже очень лаконично и понятно. «Мифы в переносном смысле - ложные, некритические, оторванные от действительности состояния сознания, концепций, представления. МИФ (от греч. mythos - предание, сказание), повествование о богах, духах, обожествленных героях и первопредках, возникшее в первобытном обществе. В первобытном обществе мифы - основной способ познания мира. Особенность мифологического сознания - установление мнимых связей между различными явлениями. Элементы мифологического мышления сохраняются и в современном массовом сознании (напр., расовые и классовые мифы, культ вождей, ритуалы массовых сборищ и т. п.)» (Миф, Электр. ресурс).

Важно отметить, что в древнегреческом языке, откуда собственно, и было заимствовано слово «миф», имелось также иное понятие, «логос», - означающее слово, рассказ или учение. Для нас это уточнение имеет большое значение в связи с трактовкой понятия «история» к которому мы сейчас и обратимся. «История (от греч. historia - рассказ о прошедшем об узнанном) 1) процесс развития природы и общества. 2) комплекс общественных наук (историческая наука), изучающих прошлое человечества во всей его конкретности и многообразии» (История, Электр. ресурс).

Обратим внимание на то, что в том и другом случае мы имеем дело с рассказом, только в случае с историей - с достоверным рассказом, а в случае с мифом - с вымышленным рассказом или «ложным и некритичным». Надо сказать, что эти «ложные и некритичные» рассказы или представления очень хорошо прижились в нашем сознании, а иногда их практически не возможно вычленить из массы критичного знания. И этому есть свои 
объяснения. Понятно, что, например, для молодежи в современном обществе основным способом познания являются отнюдь не мифы, а по большей части - средства массовой информации, где, конечно, доминирует Интернет. А вот теперь постараемся задуматься - а что «он нам несет», Интернет, этот «новый поворот», как в известной песни группы «Машины времени». Ответ очевиден - различного рода перессказы истории, либо, по большей части, мифологизированные, либо, что еще хуже, - фалисифицированные. Кстати, фальсификации сравнимы с болезнью СПИДом - заразиться легко, а вылечиться практически не возможно... Конечно, в СМИ не только мифы и фальсификации, но и еще много научных фактов и вообще много доброго, светлого и правильного, но вот только чтобы понять это «еще», надо знать подлинную историю, - как Отечества, так и желательно всемирную. А вот этим знанием наша молодежь как раз и не может похвастаться, в силу многих причин, и по большей части объективных, - но это уже тема для отдельного разговора.

Очевидно, что из всего информативного потока лучше всего усваиваются яркие и простые, легко узнаваемые картинки, чем как раз и грешат современные мифы и фальсификации. Кстати, в отличие от трудноусвояемых и тяжеловесных в смысле понимания научных знаний, да и мифов древних цивилизаций. В первую очередь, стоит вспомнить запутанные, с многоуровневым философским багажом, древнегреческие мифы о богах и героях.

Вот в нашей цивилизации издревле приняты мифы, подчиненные иной логике. В первую очередь, в них всегда читалась любовь к Отечеству. Русские мифы долгое время бытовали в форме сказаний, преданий, старин (былин) по большей части героико-патриотической, нравственноучительной или религиозной направленности. Сейчас попробуем по порядку разобраться в названных терминах, для того, чтобы получить понимание о мифе в целом. Итак, - «сказание». Термин «сказание» является переводом с древнегреческого языка и трактуется как «история», «рассказ». В древнерусской литературе понятие «сказание» применялось к любому рассказу, повествующему в основном о событиях и людях в прошлом, за редким исключением, и имеющему определённую смысловую нагрузку, которая позволяла делить сказания по тематике. Так, например, широко известны исторические сказания (например, - «Сказание о зачатии царства Казанского»); житийные сказания (например, - «Сказание страстотерпцю святую мученику Бориса и Глеба»); апокрифические («апокриф» - «ложный») сказания («Сказание о Адаме, егда изгнан бысть из рая»); поучительные сказания (например, - «Сказание о пьянстве и душегубстве») и др. В 1885 г. И. П. Сахаровым была впервые издана энциклопедия древнерусской литературы и фольклора под названием «Сказания русского народа». Стоит подчеркнуть, что когда речь идет о древних сказа- 
ниях, все же имеются ввиду записанные на бумаге рассказы, в отличие от преданий, под которыми принято понимать устное народное творчество.

«Исторический словарь» характеризует «предание» как устный рассказ, жанр фольклора, содержащий сведенияобисторическихлицах, событиях, местностях, передающийсяизпоколениявпоколение. Нередко возникнув из рассказа очевидца, подвергается при передаче вольной поэтической интерпретации (Предание, Электр. ресурс).

И, наконец, - старина или былина - эпическая народная песня героикопатриотической направленности. В первую очередь, обратимся к этимологии термина былина. «Былины (старины), русские народные эпические песни-сказания. Возникли как выражение исторического сознания русского народа IX-XIII вв., в процессе бытования впитали события позднейшего времени. Повествуют преимущественно о богатырях - защитниках родины; отразили нравственные и социальные идеалы народа. Северные былины исполняются одноголосно, обычно на короткие напевы декламационноповествовательного склада, южные былины хоровые, по музыке родственны широкораспевным донским песням» (Былины, 1: Электр. ресурс).

В «Этимологическом словаре русского языка» М. Фасмера находим некоторое уточнение: былина - «эпическая народная песня... придумано И.П.Сахаровым... Вместо “былины” в народе говорят “песня, старина” (Фасмер, 2003: 258-259). Литературная энциклопедия ещё подробнее раскрывает данный термин: «Былины - русские эпические песни, сохранившиеся главным образом в устах северного крестьянства под названием “старин”, “стари” и “старинок”. Термин “былины” искусственный, введённый в научное употребление в 30-х годах XIX века ученым Сахаровым на основании упоминаемых в “Слове о полку Игореве” (кон. XII в.) “былин сего времени”. У северных “сказителей” (исполнителей, певцов) именем старин обозначаются иногда также некоторые эпические духовные стихи и многие исторические песни, главным образом, XVI-XVII вв... Былины повествуют преимущественно о богатырях - защитниках родины. Северные былины исполняются одноголосно, обычно на короткие напевы декламационно-повествовательного склада, южные былины хоровые, по музыке родственны широкораспевным донским песням» (Былины, 2: Электр. ресурс).

Итак, «былина» - относительно новое понятие, впервые введенное в научный оборот известным фольклористом XIX века Иваном Петровичем Сахаровым в сборнике «Песни русского народа» (1839). Данное нововведение было сделано Сахаровым на основании исследования древнерусского текста - «Слова о полку Игореве», где неоднократно встречалось словосочетание «по былинам» (в понимании «быль» - события прошлого). Так, с легкой руки Ивана Петровича, русские народные эпические песни-сказания или старины начиная с XIX в. получили новое название 
- былины, коим мы до сих пор и пользуемся.

В древности былины или старины передавались из уст в уста или, вернее сказать, - напевались, первые записи былин обнаруживаются лишь в XVII веке. Очевидно, что былины за время своего устного бытования многократно переделывались и видоизменялись и вычленить из былинного эпоса, который имеется сейчас в распоряжении исследователей, былину, относящуюся, например, к X или XIII векам, практически невозможно. Начиная с XVII века, накопилось более 1500 текстов былин, при этом былинных сюжетов совсем не много, всего около 40.

Самым древним былинным текстом считается рукопись, относящиеся к началу XVII в. - «Сказание о киевских богатырях, как ходили в Царьград и как побили цареградских богатырей и учинили себе честь» (в конце текста это «Сказание» названо «Богатырским словом»). Вообще к XVII в. относятся всего лишь 5 былин, Остальные записи былин относятся уже к более поздним периодам. Среди наиболее распространенных былин русского средневековья можно назвать следующие - «Сказание о семи богатырях», «Сказание о Михаиле Потыке», «Сказание об Алеше Поповиче и Тугарине», «Сказание о Ставре Годиновиче», «Сказание о Михаиле Даниловиче», «Сказание об Илье Муромце и Соловье разбойнике». Эти прекрасные былины о русских богатырях, русской удали и любви к матушке-России и сейчас любимы современниками. Многие из них были экранизированы. Например, хорошо известны мультфильмы об Илье Муромце, Добрыне Никитиче, Алеше Поповиче.

Однако «в последние времена» легенды, сказания, предания и былины вообще вышли из обихода, а вот мифы, наоборот, продемонстрировав уникальную живучесть, стали создаваться с новой силой. К тому же, что совсем нехарактерно для мифа как жанра, создаваться они стали не только о прошедшем времени, но и о будущем. Пройдя непростой эволюционный путь, мифы новейшей истории очень упростились, порою даже до уровня слогана. Вспомним хотя бы В. Маяковского, его знаменитое «через четыре года здесь будет город сад...» Хотя, конечно, в стихотворении речь идет о городе Кузнецк, однако - воспринималось оно тогда как лейтмотив к будущей и очень скорой счастливой жизни всего советского народа, в этот миф верили и приближали как могли! Правда, чем больше трудились, тем дальше почему-то отодвигалось прекрасное будущее. Наконец, мираж исчез, - а любое отрезвление, как известно, дается очень трудно, и отдельному человеку, и человечеству в целом. И чтобы забыться, сбросить гнет воспоминаний и жить дальше - нужен новый мираж, новый красивый и желательно простой миф. Вот как описывает это в своем стихотворении Дмитрий Быков: 
Порядок обветшал, Страна упала на бок И треснула по швам, Затлела по окраинам

И двинулась на слом

Отравленным, ославленным,

Оплавленным куском.

Но мы - не та порода,

Чтоб нас пугал распад.

Через четыре года

Здесь будет город-сад!

И еще один миф разбился о рифы действительности. Однако очередное крушение отнюдь не привело к упадку мифотворчества, наоборот, спровоцировало его бурный рост. Такая жизнестойкость мифотворчества и мифов вполне объяснима - мифы дают надежду, без которой жизнь человека невозможна. Крушение старых мифов рождает к жизни новые мифы. Нереализовавшиеся надежды также рождают мифы, особенно часто это происходит в переломные эпохи, а так как наша страна богата на переломные эпохи - миф будет жить в России вечно.

Давно известно, что скелетом любого общества является система национальных ценностей. Они и формируют культурно-исторический тип на-ции, воплощающийся в системе определенных образов - архетипов, на основании которых и выстраивается самоидентификация. Влияние устной памяти и ярких литературных образов древности на историческое сознание и складывание национально-государственной идеи не раз становилось предметом внимания ученых (см.: Алексеев, 2006; Алексеев, Плотникова, 2013; Плотникова, 2014; Плотникова, Шилов, 2014). Нельзя не признать, что былины, сказания, народные предания и ряд мифов входят в систему ценностей русского человека, а значит - являются неотъемлемой частью нашей жизни и нашего Я.

Оставим на время мифы и перейдем к более сложной, а в последнее время наиболее острой для нашего общества проблеме - фальсификации истории. В этой связи вновь обратимся к определению самого термина. Итак, - «фальсификация (позднелат. falsificatio - от falsifico подделываю), 1) злостное, преднамеренное искажение каких-либо данных; 2) Изменение с корыстной целью вида или свойства предметов; подделка» (Фальсификация, 1: Электр. ресурс). Здесь будет уместным сравнить данное определение, найденное нами в Большом энциклопедическом словаре, с определением фальсификации взятым из Большой советской энциклопедии 1969-1978 гг.: «Фальсификация (позднелат. falsificatio, от falsifico подделываю) 1) злостное, преднамеренное искажение данных, заведомо 
неверное истолкование чего-либо; 2) Изменение с корыстной целью вида или свойства предметов; подделка» (Фальсификация, 2: Электр. ресурс).

Как видим, определения сходны. Однако, «Большая советская энциклопедия» уточняет: «заведомо неверное истолкование чего-либо». Вот именно таких - «заведомо неверных» толкований фактов и событий как прошлого, так и настоящего, надо опасаться, надо с ними бороться - в первую очередь, при помощи добротного критичного знания.

В нашем историческом опыте значительная часть фальсификаций имела антипатриотическую направленность. Примером одной из вопиющих фальсификаций может служить ложное мнение о развязывании Второй мировой войны Советским Союзом. Данная фальсификация получила широкое распространение после выхода в свет книги В. Б. Резуна (В. Суворова) «Ледокол», где объявляется, что летом 1941 г. основной целью внешней политики И. В. Сталина был захват Центральной и Западной Европы. Так, по мысли В. Суворова, И. В. Сталин намеревался противостоять «мировому капиталу». Книга, содержащая в себе домыслы автора, без опоры на источники и факты, быстро стала популярной - так как содержала в себе противоречие по отношению к общепринятым догмам, - была переведена на 27 языков и выдержала 100 изданий... Фальсификации истории Великой Отечественной войны многочисленны, притом что их разоблачению посвящено немало работ (см., например: Ильинский, 2013; Ручкин, 2014; Жукова, 2013; Амрахова, 2014). Однако грубым дискредитирующим искажениям, нередко из-за своей распространенности и укорененности неточно определяемым как «миф», подвергается и историческая действительность давно минувших веков (см., например: Алексеев, 2005; Алексеев, 2013; Елисеева, 2013, 2014).

Итак, если миф - это вымышленный рассказ о событиях прошлого, настоящего или будущего, возникший естественным образом, ставший неотъемлемым достоянием массового сознания, созданный в созидательных целях и при этом не искажающий истории стран и народов, оказавшихся в ойкумене мифа; то фальсификация - это вымышленный рассказ, созданный под воздействием группы лиц с целью умышленного искажения событий и фактов, исходя из конкретных политических или идеологических целей, как правило, умышленно искажающий историю как собственного народа, так и народов, входящих в ойкумену фальсификации.

К сожалению, фальсификации - это чума нашего времени, но, прежде чем бороться с ними, их надо хорошо изучить. Сегодня фальсификации научились отлично маскироваться под правду или добрый миф, теперь они носят камуфляж и пробираются в головы людей украдкой, под покровом тьмы. Но отличить фальсификацию от истории все же можно. Главной отличительной чертой любой фальсификации являются цели её 
фабрикации, где основополагающая заключается в разрушенииобщепринятых устоев, традиций и исторической правды.

В заключение заметим: мифологизировать будущее можно, а фальсифицировать - нельзя, потому что будущее всегда и во все времена представлялось человечеству прекрасным.

\section{СПИСОК ЛИТЕРАТУРЫ}

Алексеев, С. В. (2005) Литературные и археологические источники о крещении Новгорода // Знание. Понимание. Умение. № 2. С. 189-195.

Алексеев, С. В. (2006) От предания к летописи: Эволюция исторического сознания древних славян // Вопросы истории. № 1. С. 97-105.

Алексеев, С. В. (2013) Мифы екатерининского века // Знание. Понимание. Умение. № 3. С. 322-323.

Алексеев, С. В., Плотникова, О. А. (2013) Мечта о Новом Иерусалиме. Христианское обоснование власти: Византия, Болгария, Русь // Родина. № 5. C. 51-52.

Амрахова, Г. С. (2014) О юных героях войны // Научные труды Московского гуманитарного университета. № 8. С. 25-38.

Былины [1; Электронный ресурс] // Большой энциклопедический словарь. URL: http://www.vedu.ru/bigencdic/9324/ [архивировано в Website] (дата обращения: 8.02.2015).

Былины [2; Электронный ресурс] // Литературная энциклопедия. URL: http://feb-web.ru/feb/litenc/encyclop/le2/le2-0011.htm [архивировано в Website] (дата обращения: 8.02.2015)

Елисеева, О. И. (2013) Игры памяти. Проблема исторической достоверности в «Записках» Е. Р. Дашковой // Историческое обозрение. Вып. 14. С. 50-57.

Елисеева, О. И. (2014) Сентиментальный экзекутор // Научные труды Московского гуманитарного университета. № 9. С. 16-46.

Жукова, О. Г. (2013) Великая Отечественная война: от мифа к легенде // Высшее образование для XXI века. X Международная конференция. Круглый стол «Мифы и история». М. : Изд-во МосГУ. 154 с. С. 112-128.

Ильинский, И. М. (2013) Победа бесценна // Знание. Понимание. Умение. № 1. С. 3-10.

История [Электронный ресурс] // Большой энциклопедический словарь URL: http://www.vedu.ru/bigencdic/24702/ [архивировано в Website] (дата обращения: 8.02.2015).

Легенда [Электронный ресурс] // Большой энциклопедический словарь. URL: http://www.vedu.ru/bigencdic/33465/ [архивировано в Website] (дата обращения 8.02.2015).

Миф [Электронный ресурс] // Большой энциклопедический словарь. 
URL: http://www.vedu.ru/bigencdic/39220/ [архивировано в Website] (дата обращения 8.02.2015).

Плотникова, О. А. (2013) Историческое сознание современной российской молодежи // Научные труды Московского гуманитарного университета. № 8. С. 14-21.

Плотникова, О. А. (2014) Печальник земли Русской // Родина. № 5. С. $50-53$.

Плотникова, О. А., Шилов, Н. А. (2014) Идеология централизации Московского княжества (по материалам литературных памятников) // Научные труды Московского гуманитарного университета. № 8. С. 12-24.

Предание [Электронный ресурс] // Исторический словарь. URL: http:// enc-dic.com/history/Predanie-31510.html [архивировано в Website] (дата обращения: 8.02.2015).

Ручкин, Б. А. (2011) Проблема «Мифы и история»: историческое обозрение [Электронный ресурс] // Информационный гуманитарный портал «Знание. Понимание. Умение». №1. URL: http://www.zpu-journal.ru/ezpu/2011/1/Ruchkin_Myths/ [архивировано в Website] (дата обращения: 8.02.2015).

Ручкин, Б. А. (2014) 1941 год: миф «Армия не воевала» // Знание. Понимание. Умение. № 2. С. 125-131.

Фальсификация [1; Электронный ресурс] // Большой энциклопедический словарь. URL: http://www.vedu.ru/bigencdic/65882/ [архивировано в Website] (дата обращения: 8.02.2015)

Фальсификация [2; Электронный ресурс] // Большая советская энциклопедия. URL: http://dic.academic.ru/dic.nsf/bse/143893/Фальсификация [архивировано в Website] (дата обращения: 8.02.2015).

Фасмер, М. (2003) Этимологический словарь русского языка. М. : Языки славянской культуры. Т. 1.

Плотникова Ольга Анатольевна - доктор исторических наук, доцент, заместитель председателя Историко-просветительского общества «Радетель», профессор кафедры истории Московского гуманитарного университета. Адрес: 111395, Россия, г. Москва, ул. Юности, д. 5, корп. 3. Тел.: +7 (499) 374-55-81. Эл. адрес: monomach@list.ru

Plotnikova Olga Anatolyevna, Doctor of Science (history), Associated Professor, Vice-Chairperson of the Historic-Educational Society "Radetel", Professor of the Department of History of the Moscow University for the Humanities. Tel.: +7 (499) 374-55-81. E-mail: monomach@list.ru 